\title{
Implantação de um módulo agroflorestal com práticas agroecológicas no Campus Picuí, Paraíba
}

\author{
Paulo Alexandre de Aguiar ${ }^{1}$, Djair Alves de Melo ${ }^{* 2}$, Noatan dos Santos Azevedo ${ }^{3}$, Valter Silva Ferreira ${ }^{4}$, José Elson da \\ Silva Júnior ${ }^{5}$, Wagner Marinho de Andrade Filho ${ }^{6}$
}
${ }^{1}$ Instituto Federal da Paraíba, ${ }^{1}$ paulinhom_adesivos@ @otmail.com; ${ }^{\text {*2 }}$ djairifpb@gmail.com; ${ }^{3}$ noatansantos@gmail.com; ${ }^{4}$ valtersilva.nfpb@gmail.com; ${ }^{5}$ elson2056@gmail.com; ${ }^{6}$ wagnermarinho.ifpb@gmail.com.

\begin{abstract}
RESUMO: O objetivo do trabalho foi implantar um módulo de SAFs como atividade curricular no Campus Picuí-PB, visando promover o desenvolvimento técnico e socioeconômico dos alunos de Agroecologia, bem como estimular a preservação e manutenção de uma área verde denominada de Bosque florestal. A atividade de estudo foi desenvolvida no IFPB/Campus Picuí. O trabalho foi dividido em três momentos: implantação do banco de proteínas; construção de barramento; manejo do Bosque florestal e identificação das espécies. Proporcionou-se aos futuros profissionais da Agroecologia vivenciar o manejo de um módulo de SAFs. As ações realizadas no período da implantação do banco de proteínas e bosque florestal puderam contribuir para a mantença da flora local. Além da conservação da flora foi constatado no aumento de espécie da fauna como abelhas, pássaros e roedores. As ações realizadas no período da implantação do Banco de proteínas e Bosque florestal pode contribuir para a mantença da flora local. Através da implantação do Bosque florestal constata-se que o Sistema Agroflorestal cabe no âmbito da agricultura familiar, experiência que ser socializada com os demais discentes e produtores da região do Curimataú Paraibano.
\end{abstract}

PALAVRAS-CHAVE: Manejo; Pasto apícola; Produção de forragem.

\section{INTRODUÇÃO}

Dentro da matriz curricular do Curso Superior em Agroecologia sistemas agroflorestais (SAFs) traz aos discentes a importância e necessidade da implantação de SAF no semiárido Paraibano como uma ferramenta socioeconômica de grande valor para os produtores desta região. Os SAFs se apresentam como alternativa sustentável através do manejo das paisagens locais formando corredores ecológicos. Para Schroth et al., (2004) os SAFs são sistemas que contemplam no mesmo espaço físico árvores e arbustos lenhosos, assim potencializando benefícios sociais, econômicos e ambientais.

O uso contínuo e/ou simultâneo com cultivos de espécies de interesse agroecológico consorciada com espécies frutíferas, florestais e animais, usando o mesmo espaço físico associadas a técnicas de manejo compatíveis com a agroecologia. Espécies presentes no módulo de produção florestal, além de apresentar a função alimentícia, apresentam outras funções como proteção, reflorestamento de áreas degradas, pasto apícola, forragem e etc., ou seja, em SAFs é necessário o uso de plantas arbóreas, arbustivas e herbáceas, consorciadas com espécies agrícolas e forrageiras com ou sem presença animal, mas obrigatoriamente associadas às espécies florestais (ABDO et al., 2008).

Além desses aspectos, em termos sociais, os SAFs proporcionam segurança alimentar, atingida em um período relativamente curto de tempo, com uma grande diversidade de alimentos saudáveis, num sistema produtivo abundante e sem necessidade de quaisquer insumos externos (COSTA JR et al., 2009).

Portanto, objetivo do trabalho foi implantar um módulo de SAFs como atividade curricular no Campus Picuí-PB, visando promover o desenvolvimento técnico e socioeconômico dos alunos do Curso de Graduação em Agroecologia, bem como estimular a preservação e manutenção de uma área verde denominada de Bosque florestal.

Desta forma objetivou-se a implantação de um módulo agroflorestal como ambiente didático para os alunos do Curso superior em agroecologia do Campus Picuí - PB.

\section{MATERIAL E MÉTODOS}

O trabalho foi desenvolvido entre os meses de março e maio de 2019 no Instituto Federal de Educação, Ciência e

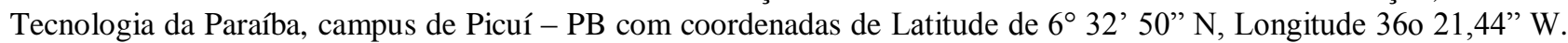
O clima do município de Picuí-PB caracteriza-se como Bsh semiárido quente, com chuvas de verão e com período de estiagem de 7 a 8 meses. A pluviometria é em torno de $339,1 \mathrm{~mm}$ e temperatura variando de $23^{\circ} \mathrm{C}$ a $25^{\circ} \mathrm{C}$, com vegetação predominante de Caatinga (BELTRÃO, 2005).

A experiência de implantação do primeiro "Bosque florestal" do Campus Picuí foi vivenciada pelos alunos do 6 período do Curso Superior em Agroecologia (CSA) do Campus-Picuí, a atividade de manejo e implantação do meliponário está ligada as atividades extracurriculares da disciplina de Sistemas Agroflorestais e Produção Animal III. A implantação do projeto veio atender a uma demanda postas pelos alunos e professor titular da disciplina juntamente com o intuito de oportunizar aos alunos das disciplinas relacionadas ao projeto, por meio do qual o IFPB disponibilizou

Caderno Verde de Agroecologia e Desenvolvimento Sustentável (ISSN 2358-2367) v. 9, n.7, e-6842, 2019 doi: $10.18378 /$ cvads.v9i7.6842 
AGUIAR, P. A. et al. Implantação de um módulo agroflorestal com práticas agroecológicas no Campus Picuí, Paraíba. In: II Congresso Paraibano de Agroecologia \& IV Exposição Tecnológica, 2019. Anais... Caderno Verde de Agroecologia e Desenvolvimento Sustentável, Pombal, v. 9, n.7, e-6842, 2019.

um espaço de área de estudos práticos, como também em ações futuras promover dias de campo os demais alunos do curso. Portanto, suprindo a necessidades de uma área experimental que venha beneficiar os alunos do Curso de Agroecologia.

O repasse das técnicas agroflorestais e construção de um banco de proteínas se deu em três momentos:

Momento 1 - No início do ano letivo (2019.1) professor e alunos da disciplina de Animal III, que trata da nutrição de animais criados no semiárido implantaram um Banco de proteínas em área comum com o Bosque florestal, ambas na área de produção agroecológica do Campus Picuí. Com características de erosão causada pela ação da energia potencial da água da chuva que promovem perda de solo, reduzindo a capacidade de armazenamento de nutrientes e água, compactando o solo. As principais espécies plantas foram: Gliricícia (Gliricidia sepium), Agave (Agave angustifolia), Leucena (Leucaena leucocephala) moringa (Moringa oleifera), Canafístula (Cassia fistula) e Capim Buffel (Cenchrus ciliaris) com o intuito de produzir alimentos, mitigação dos efeitos das voçorocas provocadas pelas chuvas, conforme figura 1.

Figura 1 - Banco de proteínas com espécies com potencial forrageiro em Picuí, PB.

Fonte: Melo (2019)

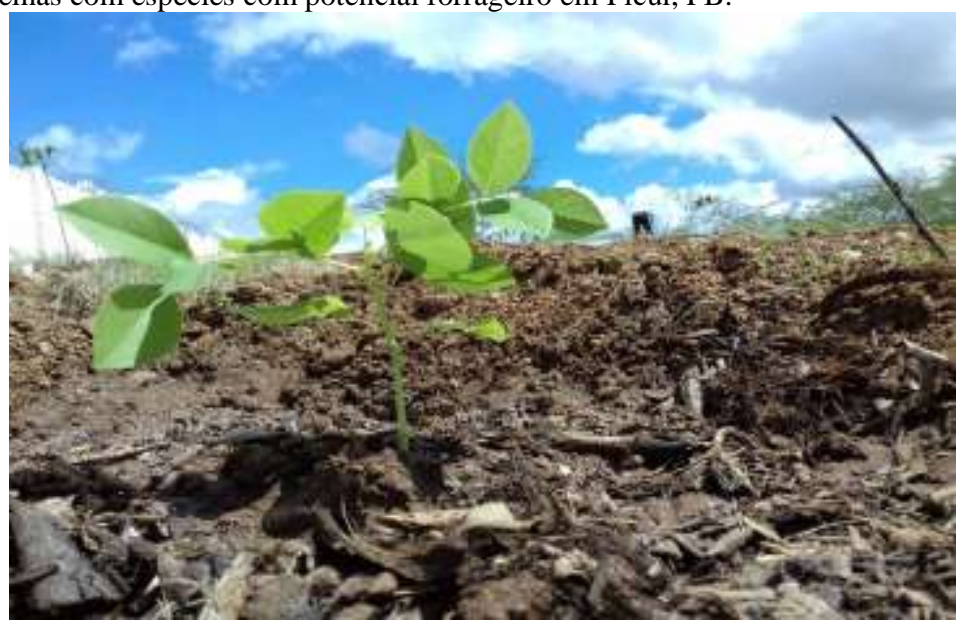

Momento 2 - Construção de barramento através de uma curva de nível para minimizar os efeitos das águas das chuvas. Os materiais utilizados para o barramento foram provenientes da área de estudo como pedras, entulho, britas, pó de rocha, galhos provenientes do manejo do Bosque florestal, seguido do cultivo de plantas com potencial forrageiro, onde as mesmas foram plantadas acima do barramento, (Figura 2 A e B).

Figura 2 - A e B Linhas de plantas forrageiras cultivas em linha de curva de nível, Picuí, PB.

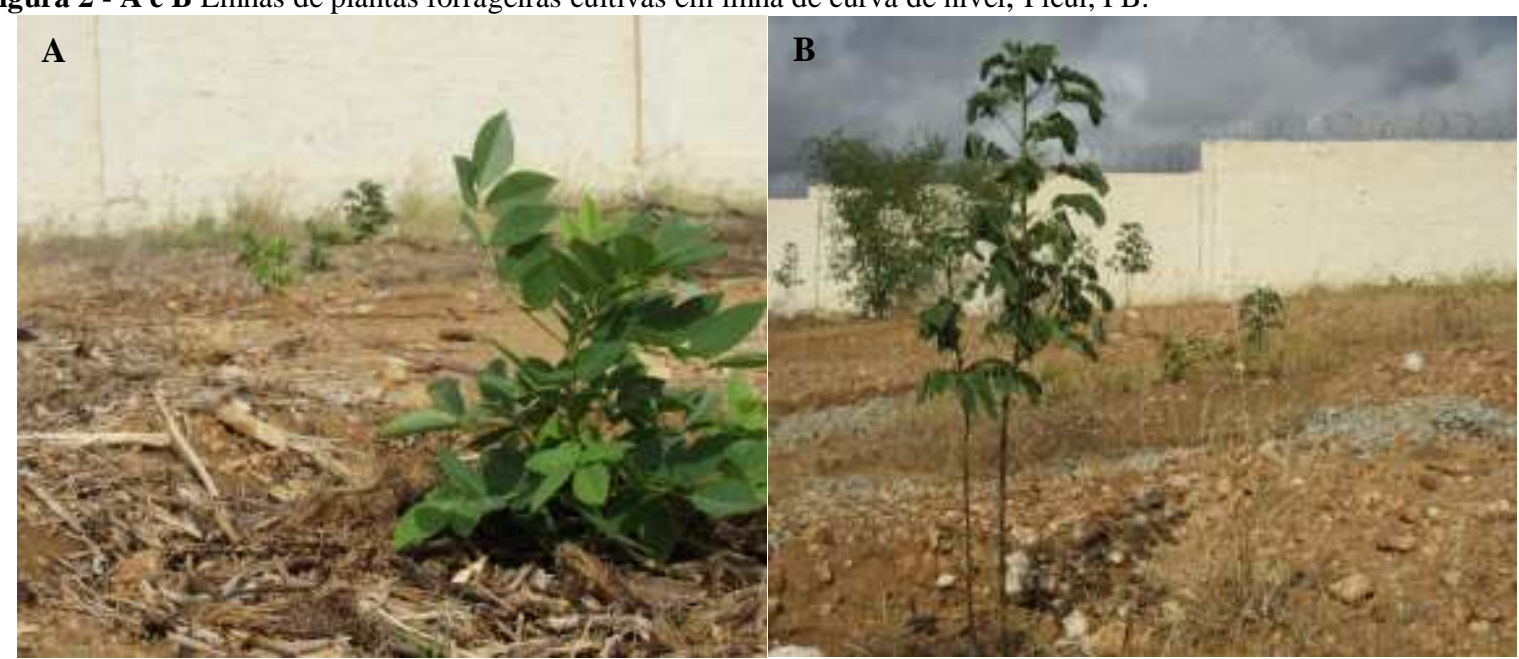

Fonte: Melo (2019)

Para reforço e proteção do barramento foi realizado o plantio do Capim Buffel (Cenchrus ciliaris), Breldroega (Portulaca oleracea) e Coroa de frade (Melocactus zehntneri) (Figura 3 A e B). 
AGUIAR, P. A. et al. Implantação de um módulo agroflorestal com práticas agroecológicas no Campus Picuí, Paraíba. In: II Congresso Paraibano de Agroecologia \& IV Exposição Tecnológica, 2019. Anais... Caderno Verde de Agroecologia e Desenvolvimento Sustentável, Pombal, v. 9, n.7, e-6842, 2019.

Figura 3 - A Barramento para amenizar os efeitos das chuvas, B Cultivo de Capim Buffel (Cenchrus ciliaris), Breldroega (Portulaca oleracea) e Coroa de frade (Melocactus zehntneri), Picuí, PB.

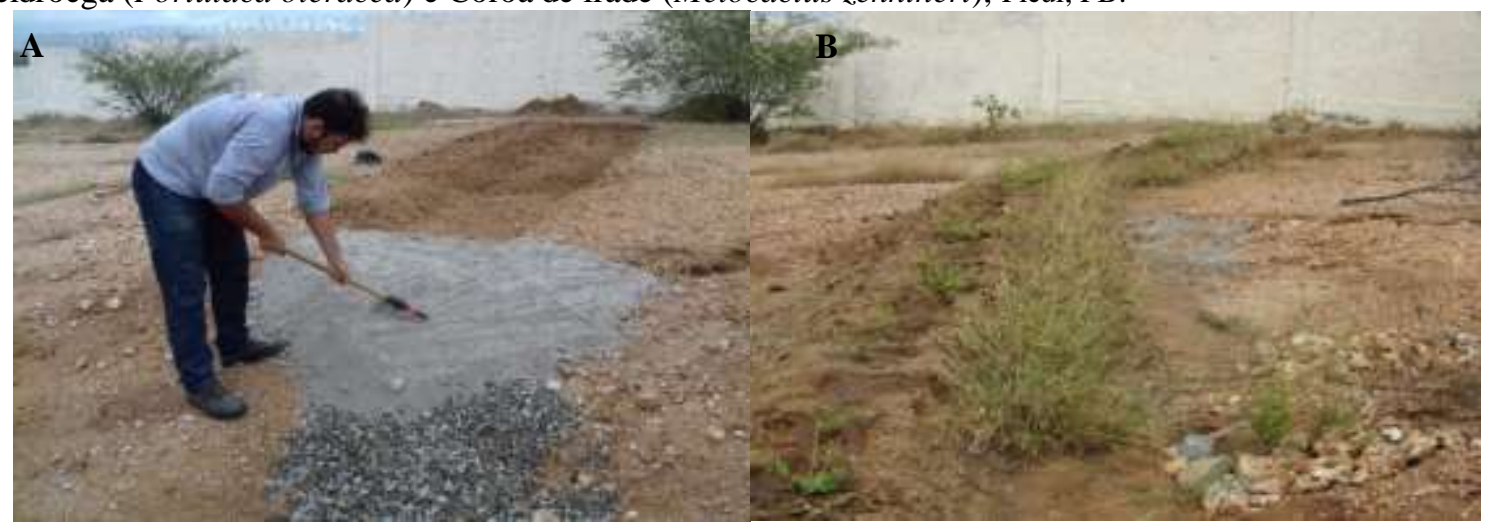

Fonte: Melo (2019)

Momento 3 - Para o manejo e preparo do Bosque florestal, os alunos realizaram a identificação das espécies contidas no ambiente, sendo definida as técnicas que seriam utilizadas para o manejo adequado, formando o bosque com o intuito de construir um ambiente didático e produtor de alimentos para uma futura instalação do primeiro meliponário do Campus Picuí (Figura 4 A e B).

Figura 4 - A Atividade de identificação, B Raleamento e rebaixamento do Bosque florestal, Picuí, PB.

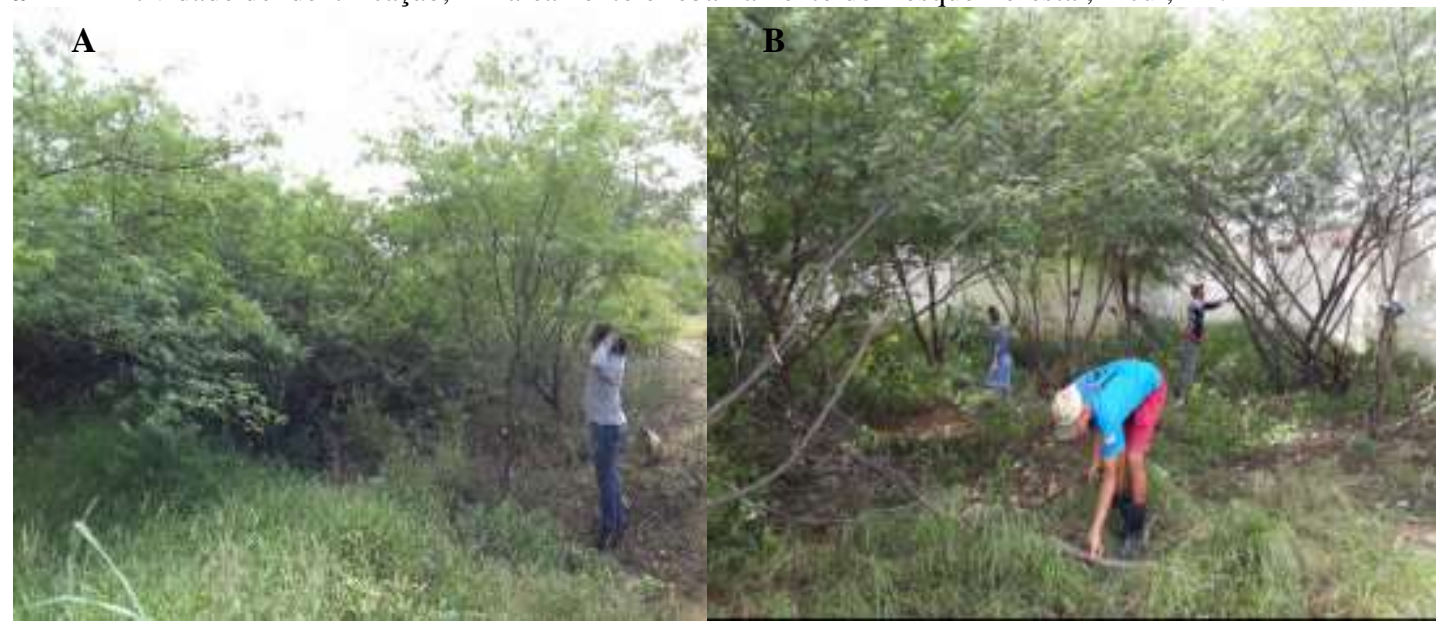

Fonte: Melo (2019)

\section{RESULTADOS E DISCUSSÃO}

O uso da produção de forragem através dos bancos de proteína torna-se uma possibilidade de alimento de qualidade e fácil acesso para os animais criados nas propriedades do semiárido, frequentemente dão prioridades as leguminosas pelo seu teor proteico e facilidade de estabelecimento em campo. Para Netto et al. (2018) a introdução de leguminosa na pastagem promove incrementos na produção animal, pelo aumento da qualidade e da quantidade da forragem, resultante não só da participação da leguminosa na dieta do animal, mas também dos efeitos indiretos relacionados com a fixação biológica de nitrogênio e seu repasse ao ecossistema de pastagem. É estratégia oportuna para propriedades que não disponibilizam de grandes áreas de pastagem, melhorando o ganho de peso dos animais.

Os SAFs proporcionam um aporte de matéria orgânica no solo favorecendo as condições físicas, química e biológica do solo, construção de microclima, função de esponja aumentando a capacidade de retenção de água e redução de lixiviação de nutrientes. O estudo de recuperação de áreas degradas por falta de cobertura vegetal se tornou um tema de discussão em quase todas instituições de ensino, pesquisa e extensão. Inúmeras pesquisas tratam da utilização estratégias para mitigação nos efeitos da degradação do meio ambiente, através da intervenção no ambiente com o uso de sucessão ecológica.

Durante a visita em loco para definição das estratégias de manejo a identificação das espécies contidas se deu através de registro fotográfico, anotações, consulta ao conhecimento popular de alguns alunos que residem na zona rural e internet. Foram identificadas onze espécies (Tabela 1). 
AGUIAR, P. A. et al. Implantação de um módulo agroflorestal com práticas agroecológicas no Campus Picuí, Paraíba. In: II Congresso Paraibano de Agroecologia \& IV Exposição Tecnológica, 2019. Anais... Caderno Verde de Agroecologia e Desenvolvimento Sustentável, Pombal, v. 9, n.7, e-6842, 2019.

Tabela 1 - Espécies identificadas no "Bosque florestal” no Campus Picuí, PB. Família, nome comum, nome científico e origem.

\begin{tabular}{llll}
\hline \multicolumn{1}{c}{ Família } & \multicolumn{1}{c}{ Nome comum } & \multicolumn{1}{c}{ Nome Científico } & \multicolumn{1}{c}{ Origem } \\
\hline Fabaceae & Algaroba & Prosopis juliflora & Deserto do Piúra - Peru \\
Fabaceae & Jurema Preta & Mimosa hostilis & Nativa \\
Fabaceae & Catingueira & Caesalpinia pyramidalis & Nativa \\
Fabaceae & Pau Pereiro & Platycyamus regnellii & Nativa \\
Poaceae & Capim buffel & Cenchrus Ciliaris & África \\
Euphorbiaceae & Pião bravo & Jatropha mollissima & Nativa \\
Agavaceae & Sisal & Agave sisalana & América Central \\
Solanaceae & Gogoia & Solanum Capsicoides & América do Sul \\
Euphorbiaceae & Mamona & Ricinus communis L & Ásia meridional \\
Capparaceae & Feijão Bravo & Cynophalla flexuosa & Nativa \\
Cactaceae & Xique xique & Pilocereus gounellei & Nativa \\
\hline
\end{tabular}

A área de implantação do "Bosque Florestal" estava sendo subutilizado, a partir das atividades desenvolvidas observou-se um ganho no uso da área pois com práticas agroecológicas e a implantação do SAFs, percebeu-se melhores em vários fatores como a melhoria no solo, ambiente agradável para visita das demais turmas, aumento da fauna, disponibilidade de pastos apícola. Para aqueles que buscam o conhecimento nesta área o projeto possibilitou uma melhor aplicabilidade das técnicas agroecológica nesse sistema.

Esta atividade proporcionou aos futuros profissionais da Agroecologia vivenciar a realidade de uma instalação de um módulo de SAFs, tendo em vista que, a maioria dos alunos não tem contato direto com esse tipo de atividade, o conhecimento que alguns possuem são de forma empírica nas suas propriedades rurais, assim foi possível associar as técnicas agroecológicas com o conhecimento repassados por seus antepassados, que em sua grande maioria se mostram bastante interessados, assim vislumbrando uma possível geração de renda a médio a longo prazo. Com a defasagem da atuação extensionista poderão multiplicar tais conhecimentos com seus familiares.

Um trabalho dessa grandeza estabelece uma relação de reciprocidade entre profissional/agricultor, a partir deste revela-se que todos os envolvidos têm um pouco para ensinar - apreender, que não é apenas quem está inserido em uma academia, mas a experiência do dia a dia também capacita as pessoas, muitas vezes estes mostram resistência diante das novas tecnologias, cabe ao profissional convencê-los que pode dar certo, e para isso é necessário conhecer esse meio rural (QUEIROZ et al., 2015).

Ao término da atividade foi perceptível ver a satisfação no rosto dos alunos, professores e instrutor, sem contar na repercussão na comunidade local e redes sociais, onde os agricultores ficaram curiosos e querendo saber quais critérios seriam necessários para que os mesmos fossem beneficiados

Praticas agroecológicas desta natureza proporcionam a interação com a natureza em busca de um entendimento e equilíbrio com o meio, pois viabiliza a produção de alimentos para os animais na região semiárida, assim estruturando o sistema de exploração zootécnica, otimizando a produção de carne e leite de boa qualidade, tornando-se um fator preponderante para a agricultura familiar do Curimataú Paraibano.

Atividades desta natureza trazem à tona a importância do profissional de ciências agrárias na contribuição socioeconômica da sociedade. Fica evidente a importância da produção de alimentos à base agroecológica com melhor valor nutricional favorecendo uma melhor qualidade de vida (QUEIROZ, 2015).

\section{CONCLUSÕES}

As ações realizadas no período da implantação do Banco de proteínas e Bosque florestal pode contribuir para a mantença da flora local.

Através da implantação do Bosque florestal constata-se que o Sistema Agroflorestal cabe no âmbito da agricultura familiar, experiência que ser socializada com os demais discentes e produtores da região do Curimataú Paraibano.

\section{REFERÊNCIAS}

ABDO, M. T. V. N.; VALERI, S. V.; MARTINS, A. L. M. Sistemas Agroflorestais e Agricultura Familiar: Uma parceria interessante. Revista Tecnologia \& Inovação Agropecuária, p. 50-59, 2008.

BELTRÃO, B. A.; MORAIS, F.; MASCARENHAS, J. C.; MIRANDA, J. L. F.; SOUSA JÚNIOR, L. C.; MENDES, V.A. Projeto Cadastro de Fontes de Abastecimento por Água Subterrânea Estado de Paraíba. Diagnóstico do município de Picuí. Recife, setembro de 2005. 
AGUIAR, P. A. et al. Implantação de um módulo agroflorestal com práticas agroecológicas no Campus Picuí, Paraíba. In: II Congresso Paraibano de Agroecologia \& IV Exposição Tecnológica, 2019. Anais... Caderno Verde de Agroecologia e Desenvolvimento Sustentável, Pombal, v. 9, n.7, e-6842, 2019.

COSTA JR, E. A.; GONÇALVES, P. K.; RUAS, N.; GONÇALVES, A. C.; PODADEIRA, D. S.; PIÑARODRIGUESA, F. C. M.; LEITE, E. C. Estratégias Inovadoras em ATER Voltados à Transição Agroecológica e ao Desenvolvimento de SAFs: o Caso do Assentamento Ipanema, Iperó/SP. Revista Brasileira de Agroecologia, v. 4, n. 2, p. 4332-4336, 2009.

NETTO, A. J.; ALENCAR, E. J. S.; MACÊDO, A. J. S.; SILVA, A. M. A. Uso de banco de proteínas em sistemas silvipastoris. II Congresso Internacional da Diversidade do Semiárido. Anais II CONIDIS. V.1. 2017 Campina Grande-PB. 2017.

QUEIROZ, M. J.; MELO, D. A.; FREIRE, J. L. O.; ALBUQUERQUE, R. S. Implantação do projeto pais no Sítio Cardeiro município de Picuí - PB. VII Simpósio brasileiro sobre meio ambiente e desenvolvimento sustentável do semiárido. Anais. Mossoró-RN. 2015.

SCHROTH, G. et al. Agroforestry and Biodiversity Conservation in Tropical Landscapes. Washington: Island Press, 2004.

\section{AGRADECIMENTOS}

Apoio financeiro: Fundação de Apoio à Pesquisa do Estado da Paraíba - FAPESQ. 